\title{
Extraction and Phytochemical Screening of the Root and Leave of Annona Senegalesis(Wild Custad Apple)
}

\author{
Idayat Shade ljaiya \\ Samira Arzika \\ Musliu Abdulkadir \\ College of Science and Technology \\ Waziri Umaru Federal.Polytechnic, Birnin Kebbi, Nigeria
}

\author{
Doi:10.5901/ajis.2014.v3n7p9
}

\begin{abstract}
A large number of plants are claimed to possess the antibiotic properties in the traditional system and are also used extensively by the tribal people worldwide. It is now believe that nature has given the cure of every disease in one way or another. Anonna senegalensis also known as wild custard apple has been known to relieve various diseases in Nigeria. Therefore, it is due necessary to evaluate and characterize various phytochemical constituents of the plant. In this present research, an attempt has been made to extract and evaluate the phytochemical constituents of this plant. It was found out that water and ethanol extract of the leaves and roots of Annona senegalensis were positives for flavonoid, tannis, cardiac glycoside, saponins, alkaloid, steroid, and volatile oils, but negative for saponins glycoside and Antraquinone. The leaf water extract was negative for glycoside while others were positive. The ethanol extract in both cases (leave and root) has higher activity as compared to the aqueous extract. It is concluded that Annona senegalensis possess some vital phytochemical components that can be use medically.
\end{abstract}

\section{Introduction}

The plant wild custard apple also known as Annonasenegalensis belongs to the family annoniaceae. This plant has four genera. The species A.senegalensis is widely used for food and medicinal properties. Wild custard apple occur both monoecious and diecious plant (Katendered et al., 1995). Genus Annona have both male and female parts, but the stigma is generally not receptive at the time the pollen is shed. Battles of several species are important in carrying out natural pollination. But complete pollination may be unproved both yield and quality of the fruit. The propagation method is generated through seed not leave, suckers and coppice is possible on disintegration of the fruit seed fall to the ground where cultivated or burnt areas for plant that are to be raised in the nursery scarifications improves germination rates. Root, sucker are producedon wounding of root by fire and transplanting by cultivators and animals. The plant is a sprawling shrub a tree of $20 \mathrm{ft}(6 \mathrm{~m})$ high with smooth silvery back, the leave are aromatic deciduous alternate blue green above downy prominently varied beneath in flowers bone single $r$ in pairs in leaf oxiles stalks $1 \frac{1 / 2}{2}$ in $(2.5-4 \mathrm{~cm})$ long are clasp by a 3 parted calyx and petal 3 triangular thick waxy, velvety whitish outer statements. Typically compound the pineapple scented frit but with the carpers distinctly outlined on the surface yellow or orange when ripe rounded oval 1-4 in $(2.5-10 \mathrm{~cm})$ long fleshy, seeds. Bark, leaves, flowers, roots, fruits, seeds, etc. that is any part of the plant may contain active components. The systematic screening of plant species with the purposes of discovering new bioactive compounds is a routine activity in many laboratories. Scientific analysis of plant components follows a logical pathway. Plants are collected either randomly or by following leads supplied by local healers in geographical areas where the plants are found (Adebayo, 2001).

Fresh or dried plant materials can be used as a source for the extraction of secondary plant components. Many authors had reported about plant extract preparation from, the fresh plant tissues. The logic behind this comes from the ethno medicinal use of fresh plant materials among the traditional and tribal people. But as many plant are used in the dry form (or as an aqueous extract) by traditional healers and due to differences in water content within different plant tissues. Plants are usually air dried to a constant weight before extraction. Others researchers dry the plants in the oven at about $40^{\circ} \mathrm{C}$ for 72 hours. In most of the reported works, underground parts (roots, tuber, rhizome, bud etc.) of a plant were used extensively compared with other above ground parts in search for bioactive compounds possessing 
antimicrobial properties (Owonubi, 1998)

Plant derived substances have recently become of great interest owing to their versatile applications. Medical plant are the richest bio-resource of drugs of traditional systems of medicine, modern medicines, pharmaceuticals, food supplements, flock medicines, pharmaceutical intermediates and chemical entities (Ncube et al., 2008).

In the early $14^{\text {th }}$ century, herb were used for treating diseases based on the similarity in shape between the leave if the plant and the part of the body suffering from the diseases e.g. plant with heart shaped leaves where used for treating heart diseases, while plant excluding milky juices were believed to increase lactation in women. Most of the medicinal plant are common, but easily over looked especially by urban settlers, they can be seen growing near houses and road sides and pathways. A lot of the drugs that orthodox medicinal professionals used are derived from plant sources isolated and then extracted before turned into a standardform (Katendered et al., 1995).

The use of plant to cure disease is older than man himself. Animals are naturally drawn to certain plant materials when sick, even when they are substantially carnivorous. Man has always been dependent on the plant. Recently, the field of ethno-medicine, it has been discovered that therapeutic efficacy was mere pronounced when the active compound was left in a particular combination with other principles, naturally present in plants than when it was isolated and synthesized in the laboratory. In his work on medicinal value in the south east parts of Nigeria, this is a follow up attempt at determining the types of flavonoids and amounts of phenolic compound, compounds presents in the plants species perhaps. It is this discriminating occurrence that makes the various species efficacious in the treatment of different ailment even if they belong to the same family (Obute, 2005).

Extraction (as the term is pharmaceutically used) is the separation of medicinally active portions of plant and animal tissues using selective solvents through standard procedures. The products so obtained from plants are relatively complex mixtures of metabolites, in liquid of semi-solid state or (after removing the solvent) in dry powder form, and are intended for oral or external use. These include classes of preparations known as decoctions,

Infusions, fluid extracts, tinctures, pilular (semi solid) extract or powdered extracts. Such as preparations have seen popularly called gelenicals, named after Gelen, the second century Greek physician (Remington, 2010)

Extraction methods used pharmaceutically involves the separation of medicinal active portions of plant tissues from the inactive/inert components by using selective solvents. During extraction, solvents diffuse into the solid plant material and solubilize compounds with similar polarity (Fajimi et al., 2001).

The purpose of standardized extraction procedures for crude drugs (medicinal plant parts) is to attain the therapeutically desired portions and to eliminate unwanted materials by treatment with a selective solvent known menstrum. The extract thus obtained, after standardization, may be used as medicinal agent as such in the form of tinctures or fluid extracts or further processed to be incorporated in any dosage from such as tablets and capsules. These products contain complex mixture of many medicinal plant metabolites, such as alkaloids, glycosides, terpenoids, flavonoids and liqnans (Handa et al, 2008).

The general techniques of medicinal plant extraction include maceration, infusion, percolation, digestion, decoction, hot continuous extraction (soxhlet), aqueous - alcoholic extraction by fermentation, counter current extraction, microwave-assisted extraction, ultrasound extraction (sonication), supercritical fluid extraction, and phytonic extraction (with hydroflourocarbon solvents). For aromatic plants, hydrodistillation techniques (water distillation, steam distillation water and steam distillation), hydrolytic maceration followed by distillation, expression and effleurage (cold fat extraction) may be employed. Some of the latest extraction methods for aromatic plants include head pace trapping, solid phase micro extraction, protophast extraction, microdistillation, thermomicrodistillation and molecular distillation (Handa et al, 2008).

\section{Aims and Objective}

1. To extract and determine qualitatively the phytochemical constituent of wild custard apple which will serve as preliminary investigation of medicinally active compound of the plant.

2. To obtain crude water/aqueous extract of the plant (leave and root).

3. To obtain crude ethanol extract of the plant (leave and root)

\section{Choice of Solvents}

Successful determination of biologically active compounds from plant materials is largely dependent on the type of solvent used in the extraction procedure. preparation of a good solvent in plant extractions will includes, low toxicity, ease 
of evaporation at low heat, promotion of rapid physiologic absorption of the extract, preservative action inability to cause the extract to complex or dissociate. The factors affecting the choice of solvent are quantity of phytochemicals to be extracted, rate of extraction, diversity of different compounds extracted, diversity of inhibitory compounds extracted, ease of subsequent handling of the extracts toxicity of the solvent in the bioassay process, potential health hazard of the extractants (Bimakr, 2010).

Thechoice of solvent is influenced by what is intended with the extract. Since the end product will contain traces, of residual solvent, the solvent should be non-toxic and should not interfere with the bioassay. The choice will also depend on the targeted compounds to be extracted (Ncube et al, 2008).

The various solvents that are used in the extraction procedures are:

\subsection{Water}

Water is universal solvent, used to extract plant products with antimicrobial activity. Though traditional healers use primarily water but plant extracts from organic solvents have been found to give more consistent antimicrobial activity compared to water extract. Also water soluble flavonoids (mostly anthocyanins) have no antimicrobial significance and water soluble phenolics only important as antioxidant compound (Handa et al, 2008).

\subsection{Alcohol}

The higher activity of the ethanol extracts as compared to the aqueous extract can be attributed to the presence of higher amounts of polyphenols as compared to aqueous extracts. It means that they are more efficient in cell walls and seeds degradation which have unipolar character and cause polyphenols to be released from cells. More useful explanation for the decrease in activity of aqueous extract can be ascribed to the enzymes polyphenol oxidase, which degrade polyphenols in water extract were as methanol and ethanol they are inactive. Moreover, water is a bitter medicine for the occurrence of micro-organisms as compared to ethanol (Laponik et al, 2005). The higher concentrations of more bioactive flavonoid compounds were detected with ethanol $70 \%$ due to its higher polarity than pure ethanol. By adding water to the pare ethanol up to 30\% for preparing ethanol 70\% the polarity of solvent was increased (Bimakr, 2010). Additionally, ethanol was found easier to penetrate the cellular membrane to extract the intracellular ingredients from the plant material (Wang, 2010). Since nearly all of the identified components from plants active against microorganisms are aromatic or saturated organic compounds, they are most often obtained through initial ethanol or methanol extraction. Methanol is more polar than ethanol but due to it cytotoxic nature, it is unsuitable for extraction in certain kind of studies as it may lead to incorrect results (Cowan, 1999).

\section{Materials and Methods}

\subsection{Sample collection}

The leave and roots of Annona senegalensis (Gwandan Daji) in Hausa language was collected from Bayan Kara area in Birnin Kebbi, Kebbi State. The collected leaves and roots were air dried, grinded and kept till when needed for the analysis.

\subsection{Extraction techniques}

The plant's active ingredients were obtained by extraction method described by (Junaid et al., 2006). This procedure was used for both cold water and ethanol extract. This was obtained by soaking $40 \mathrm{~g}$ of the grounded (sieved) sample in $350 \mathrm{ml}$ of distilled (cold water extract) in a sterile conical flask and left to stand for 24 hours was then filtered with sterile filter paper (Watman no.1) after which the filtrate was then evaporated in a water bath at $100^{\circ} \mathrm{C}$ to evaporate excess water. The extract obtained was then stored in refrigerator for further investigation.

The same procedure was adopted for ethanol extract except the ethanol was evaporated at $78^{\circ} \mathrm{C}$.

\subsection{Phytochemical analysis of crude extract}

The following analysis was carried out on both water and ethanol crude extract of Annona senegalensis so as to evaluate 
the presence of the following elements or compound in them which were given below:

\subsubsection{Test for Tennins (Ferric Chloride Test)}

A little portion of water extract was diluted with water in the ratio of 1:4 and few drop of 10\% ferric chloride solution was added, a blue or green colour indicated the presence of Tannis (Manga and Oyeleke, 2008).

\subsubsection{Test for Alkaloides}

$0.5 \mathrm{~g}$ of each extract was stirred with $5 \mathrm{~cm}^{3}$ of $1 \%$ aqueous hydrochloric acid on a steam bath. $1 \mathrm{~cm} 3$ each of the filtrate was treated, and then it was treated separately with a few drops of Drangedrorfts reagents, Meyer's reagent and Wagner's reagents. A deep brown creamy precipitate indicates a positive test (Manga and Oyeleke, 2008).

\subsubsection{Test for Balsams}

2 drops of alcoholic ferric chloride solution was added to $5 \mathrm{~cm}^{3}$ of $90 \%$ each of the extract. A dark green colour indicates the presence of balsams. (Manga and Oyeleke, 2008).

\subsubsection{Test for Saponins}

$10 \mathrm{mls}$ of distilled water was added to $0.5 \mathrm{~cm}^{3}$ of each extract. Shake the content vigorously with the test tube for 2 minutes. The presence of frothing or bubbling indicates the presence of saponins (Manga and Oyeleke, 2008).

\subsubsection{Test for Steroids}

5 drops $\mathrm{f}$ concentrated $\mathrm{H}_{2} \mathrm{SO}_{4}$ was added to $1 \mathrm{~cm}^{3}$ of the extract. A reddish brown colour indicates the presence of steroids (Manga and Oyeleke, 2008).

\subsubsection{Test for Flavonoids}

$1 \mathrm{ml}\left(1 \mathrm{~cm}_{3}\right)$ of each extract was dissolved in $2 \mathrm{mls}$ of sodium hydroxide solution. The appearance of a yellow solution which disappeared on addition of hydrochloric acid indicates the presence of flavonoids (Manga and Oyeleke, 2008).

\subsubsection{Test for Free Anthraquinones (Bumtrager's)}

$0.5 \mathrm{~g}$ of the powdered sample was taking in separate test tube and $10 \mathrm{mls}$ of chloroform was added then shake for 5 minutes again. Then the extracts were filtered and shake again. A bright pink colour in the upper aqueous layer indicates the presence of free anthraquinones (Manga and Oyeleke, 2008).

\subsubsection{Test for Cardiac Glycosides (Keller-Killiani TEST)}

$0.5 \mathrm{~g}$ of each extract was dissolved in $3 \mathrm{~cm}^{3}$ of $\mathrm{FeCl}_{2}$ (ferric chloride) in glacial acetic acid and leave for a minute. $15 \mathrm{~cm}^{3}$ of concentrated $\mathrm{H}_{2} \mathrm{SO}_{4}$ was added with the aid of pipette, so that it runs down the side of the test tube. A clear interphase with a blue layer indicates the positive test (Manga and Oyeleke, 2008).

\subsubsection{Test for Resins}

$15 \mathrm{mls}$ of petroleum ether from $0.1 \mathrm{~g}$ of each of the powdered samples was prepared and filtered into a test tube. Equal volumes of copper acetate solution were added and shake vigorously, and then allow to separate. A green colour indicates the presence of resins (Manga and Oyeleke, 2008). 


\subsubsection{Test for Carbohydrates (General Fehling Test)}

$1 \mathrm{ml}$ of fehling's $\mathrm{A}$. (CuSO 4$)$ and $1 \mathrm{ml}$ of fehling $\mathrm{B}$. (Akaline titrate) was measured and mixed, then $8 \mathrm{mls}$ of distilled water was added. $1 \mathrm{ml}$ of the mixture was added to $1 \mathrm{ml}$ of each sample, mixed and allow to react at room temperature for 5 minutes the colour changes was noted. It was placed in beaker containing warm water $\left(45-50^{\circ} \mathrm{C}\right)$ for 5 minutes the colour change was also noted. The beaker was heated so that water boils and the colour change was also noted. A positive reaction is change of colour from blue to green or orange (Manga and Oyeleke, 2008).

\subsubsection{Test for Terpenes (Liebermain-Burchard Test)}

The first portion of the chloroform solution from extract with $1 \mathrm{ml}$ of acetic anhydride was mixed and $1 \mathrm{~cm}^{3}$ of concentrated sulphuric acid was added down the wall of the test tube to form a layer under earth. The formation of a reddish violet colour indicates the presence Terpenes (Manga and Oyeleke, 2008).

\section{Result}

The result of the ethanol and aqueous extraction and phytochemical analysis of the root and leave of Annonasenegalensis were presented in table 1 and 2.

Result of Phytochemical Analysis of Ethanolic and aqueous Leaf Extract of Annona senegalensis
\begin{tabular}{|l|c|c|}
\hline Bioactive component & Ethanol & Water \\
\hline Tannins & +++ & + \\
\hline Alkaolids & + & + \\
\hline Cardiac glycoside & +++ & ++ \\
\hline Saponins & + & + \\
\hline Steroid & ++ & + \\
\hline Volatile oil & + & + \\
\hline Saponins glycoside & - & - \\
\hline Glycoside & +++ & + \\
\hline Flavonoid & +++ & - \\
\hline Anthraquinone & - & \\
\hline
\end{tabular}
Key: $+=$ positive; - negative

Result of Phytochemical Analysis of Ethanolic and aqueous Root Extract of Annona senegalensis

\begin{tabular}{|l|c|c|}
\hline Bioactive component & Ethanol & Water \\
\hline Tanins & ++ & + \\
\hline Alkaolids & + & + \\
\hline Cardialglocized & +++ & + \\
\hline Saponins steroid & ++ & +++ \\
\hline Volatile oil & ++ & + \\
\hline Saponins glycoside & - & - \\
\hline Glycoside & ++ & + \\
\hline Antraquinone & - & - \\
\hline Flavonoid & ++ & + \\
\hline
\end{tabular}

\section{Discussion Conclusion and Recommendation}

\subsection{Discussion}

Plant are potent biochemists and have been components of phytomedicine since times immemorial, man is able to obtain from them a wondrous assortment of industrial chemicals. Plant based natural constituent can be derived from any part of the plant like back, leave, roots, fruits, seed etc. Any part of the plant may contain active components. (Parekh et al., 2006).

Annonasenegalensis has been found active on parasites and some opportunistic bacteria like Pseudomonas, Staphilococcus aureus, Salmonella typhi, Shigella (Ogbadoyi et al., 2007). Therefore the synthetic and phytochemical 
screening of this plant with purpose of discovering new bioactive compounds is a routine activity in many laboratories. In this research work it was found out that water and ethanol extract of the leaves and roots of Annonasenegalensis were positives for flavonoid, tannis, cardiac glycoside, saponins, alkaloid, steroid, and volatile oils, but negative for saponins glycoside and Antraquinone. The leaf water extract was negative for glycoside while others were positive. The ethanol extract in both cases (leave and root) has higher activity as compared to the aqueous extract. This can be attributed to the presence of higher amounts of polyphenols as compared to aqueous extracts. It means that they are more efficient in cell walls and seeds degradation which have unipolar character and cause polyphenols to be released from cells. More useful explanation for the decrease in activity of aqueous extract can be ascribed to the enzyme polyphenol oxidase, which degrades polyphenols in water extracts, where as in ethanol it is inactive. Moreover, water is a better medium for the occurrence of the microorganisms as compared to ethanol. (Laporrik, et al., 2003).

Prashant, (2011) stated that: the mechanisms of action of the bioactive components confirm the antiparasitic and antibacterial action of Annonasenegalensis. Flavounoids complex with cell wall and binds to adhesion and also inhibits release of autocoids and prostaglandins. Tannis also bind to adhesions, inhibits enzyme, and may also complex with cell wall, it also make intestinal mucosa more resistant and reduce secretion. Alkaloids interelates into cell wall and also in DNA of parasite, it also possess anti-oxidation effects, thus reduces nitrate generation which is useful for protein synthesis. Glycosides inhibits release of autocoids steroids enhances intestinal absorption of $\mathrm{Na}^{+}$and water. Saponins aids vacuolization and disintegration of teguments and also inhibit histamine release in vitro. The presences of these phytochemical components and their mechanism of action confirmed their antibacterial activity on some opportunistic pathogenic bacteria.

\subsection{Conclusion}

Variations of phytochemical present in medical plant depend on solvents use for extraction and the extraction procedure. It is concluded that Annonasenegalensis possess some vital phytochemical components that can be used medically. The study thus provides further evidence on the traditional usage of this plant in treating diseases.

\subsection{Recommendation}

Due to the presence of some bioactive components in this plant (i.e. leaves and roots), it is suggested that the plant extract may be used to produce medicated soaps, antiseptic, drugs and other pharmaceutical product for treatment of infection cause by these organisms.

Secondly further investigation should be done to find out it real bioactive component and as well as its efficacy in the treatment of some diseases in vitro and in vivo.

And finally there should be further research to assess the plant level of selective toxicity.

\section{References}

Adebayo A.A. (2001) Ethnological Studies of some medical plants from Lagos State of Nigeria. Nigerian Journal of Botany (4); $72-76$

Bimakr, M. (2010). Comparison of different extraction methods for the extraction of major bioactive flavonoid compounds from spearmint. Food bio production, process 4; 1-6

Cowan, M.M. (1999). Plant products as antimicrobial agents. Clinical microbiology reviews 12 (4): 564-582

Fajimi, A.K.A.A, Ayodoji, H., Adebowale E.A and Ogundola F.L. (2001). Therapeutic trials on gastro intestinal helminthes parasites of goat busing paw paw seeds as a drench proceeding of the informational conference on sustainable crop. Livestock production for improved livelihood and natural resources management, West Africa International Institute of Tropical Agriculture.

Handa S.S., Khanuja S.P.S, Longo G and Rakesh D.D. (2008).Extraction Technologies for medicinal and aromatic plants, international centre for science and high technology, Trieste. 2: $21-25$.

Junaid S.A, Olabode A.O, Onwuliri F.C, Okworiu A.E.J and Agina S.E (2006); "The antimicrobial gastronestinal isolate". Africa Journal biothecchnology 5 (22): 23315-2321.

Katendered, A.B, Bernie, A.N.N. and Tengnas, B.O (1995); "Identification, propagation and management for agriculture and pastoral communities". Useful trees and shrubs for Uganda. Pp. 104-613.

Kippax J.O. (1999); "The useful plants of West African Trees" Royal botanic Garden, $2^{\text {nd }}$ edition, Vol. 2, Edinburgh, Churchill Livingstone, Pp. 1-6.

Lapornik B., Prosek M and Wondra, A.G. (2005). Comparison of extracts prepared from plant by-products using different solvents and extraction time. Journal of Food Engineering. 71: 214-222.

Manga, B.S. and Oyeleke, S.B. (2008). Essentials of Laboratory Practical in Microbiology. First Edition. Tobest Publisher Pp. 93-98. 
Ncube N.S., Afolayan A.J. and Okoh A.L. (2008). Assessment techniques of antimicrobial properties of natural compounds of plant origin: current methods and future trends. African Journal Biotechnology. 7 (12): 1797-1806.

Obute, G.C (2005); Ethno-medicinal plant resources of South Eastern Nigeria retrieved from http://www.sivieduel.com estetslobute Ltml.

Ogbadoyi E.O., Abdulganiyu A.O., Adana T. Z. and Okogun J.J. (2007).In vivo Trapanocidal activity of Annona senegalensis leaf extract against $T$. brucei. 112: 85-89

Owonubi M.O. (1998); "Use of local herbs for curing disease". Journal of clinical pharmacy and herbal medicine, 4 (2): 22-23.

Prashant, T., Bimlesh, K., Mandeep K., Gurpreet K. and Haleen K. (2011).Phytochemical screening and extraction.International Pharmaceutical science. 1: 98-104.

Ruskin, F.R, Bostid Elizabeth M. and Brent. S. (1991); "Neem A Tree for solving Global problem" National Academy Press Washington DC.

Remington J.P. (2010). The Science and Practice of Pharmacy, 21st edition, Lippincott Williams and Wilkins press.pp773-774.

Wang G.X. (2010). In vivo anti elmintic activity of five alkaloids from Macelya microcarpa against Dactylogyrus intermedius in Carassius auratus.Veterinary Parasitology. 171:305-313. 